\title{
Climate uncertainty and economic development: evaluating the case of Mozambique to 2050
}

\author{
Channing Arndt • James Thurlow
}

Received: 18 March 2013 / Accepted: 12 November 2014 / Published online: 28 November 2014

(C) UNU-WIDER 2014

\begin{abstract}
We apply a probabilistic approach to the evaluation of climate change impacts in Mozambique. We pass a distribution of climate shocks through a series of structural biophysical models. The resulting joint distributions of biophysical outcomes are then imposed on a dynamic economywide model. This framework produces distributions of economic impacts of climate change thus identifying an explicit range of potential economic outcomes and associating probability levels with given sets of outcomes. For example, we find that the economy of Mozambique may be up to $13 \%$ smaller in 2050 compared with a fictional no climate change scenario (and assuming global policy fails to constrain emissions growth). The probability of gross domestic product (GDP) declines of greater than $10 \%$ is relatively small at $2.5 \%$. These large declines are principally the result of dramatic reductions in flood return periods. To 2050, about $70 \%$ of future climates result in GDP losses of between zero and five percent. In about $9 \%$ of cases, climate change shocks result in higher GDP outcomes. We conclude that, relative to current practice, this structural probabilistic approach provides (i) significantly more information to decision-makers, (ii) more detailed insight into the importance of various impact channels, and (iii) a more holistic and comprehensive approach for evaluating adaptation options.
\end{abstract}

\section{Introduction}

In this special issue, a series of articles have addressed a range of important aspects of climate change including implications for crop production, runoff, irrigation demand, flood frequency and intensity, road infrastructure, hydropower, and the combination of sea level rise and cyclone strike. This article aggregates the biophysical outcomes from the preceding articles in order to estimate the implications of climate change for economic growth and development

This article is part of a Special Issue on "Climate Change and the Zambezi River Valley" edited by Finn Tarp, James Juana, and Philip Ward.

C. Arndt $(\bowtie)$

World Institute for Development Economics Research, United Nations University, Katajanokanlaituri 6 B, FI-00160 Helsinki, Finland

e-mail: Channing@wider.unu.edu

J. Thurlow

Development Strategies and Governance Division, International Food Policy Research Institute, Washington, DC, USA 
prospects. In so doing, correlations across impacts are captured. For example, relatively dry climate scenarios may have negative implications for crop and hydropower production but may also reduce costs of maintaining road networks. We focus on Mozambique, which is a representative country within the Zambezi River Valley and is also reasonably typical of lowincome agrarian economies in Sub-Saharan Africa.

To do this, we employ a dynamic economywide model with substantial sectoral detail calibrated to a detailed snapshot of the Mozambican economy in 2007. The inputs into the economywide model arrive in the form of distributions of annual weather shocks driven by a hybrid frequency distribution (HFD) of 6800 possible future climate outcomes (Schlosser and Strzepek 2013) summarized to 426 representative future climates using the approach described by Arndt et al. (2014). These 426 climates are designed to represent the best possible approximation to the distribution of future climates given the information available today and under the assumption that global mitigation policy regimes fail to constrain emissions growth. With a distribution of biophysical impacts driven by climate variations, the economywide model generates distributions of economic outcomes. For example, we estimate the HFD of average gross domestic product (GDP) levels relative to a hypothetical "no climate change" baseline, where historical climate patterns simply repeat themselves.

The estimation of HFDs on outcomes, in our view, productively shifts the terms of the debate. Suppose that we define the impacts of climate change as being "substantial" if they result in a greater than $10 \%$ reduction in GDP by 2050 relative to a "no climate change" baseline. An earlier study for Mozambique, using four future climate scenarios, indicated that this is possible (Arndt et al. 2011). Our analysis, based on 426 future climates and more refined versions of the biophysical and economic models, indicates that these outcomes are possible but unlikely. Specifically, our model results indicate that the probability of a reduction in GDP of greater than $10 \%$ is about $2.5 \%$, or the chances are about one in 40 . Attaching probabilities to the range of economic outcomes from climate change provides a more robust empirical basis for evaluating the opportunity costs of adaptation investments.

The remainder of this article is structured as follows: Section 2 presents the economic structure of Mozambique and briefly describes the economywide model employed for the economic impact analysis. Section 3 discusses the shocks drawn from the preceding articles in this volume, focusing on the case without global climate policy (i.e., the unconstrained emissions scenario). Section 4 presents results with a focus on impacts on the level of real GDP around 2050, and the net present value (NPV) of GDP losses (or gains) to 2050. The structural approach employed allows us to decompose the growth and NPV effects by impact channel and through time. The final section concludes that the probabilistic approach employed offers at least three distinct advantages relative to current practice where a limited number of climate scenarios are analyzed.

\section{Economic structure and model}

\subsection{Economic structure}

Table 1 summarizes Mozambique's trade and production structure in 2007, which is the base year for our analysis. At market exchange rates prevailing in 2007, Mozambican GDP amounted to almost nine billion US dollars (USD). Dividing this by a population of about 21 million yields per capita GDP of about USD420 per annum or somewhat more than one USD per person per day. However, incomes are not distributed evenly throughout the population. About $70 \%$ of the population is rural and $80 \%$ depend upon agriculture for their 
Table 1 Mozambique's production and trade structure, 2007

\begin{tabular}{llllll}
\hline & \multicolumn{2}{l}{ Share of total (\%) } & & $\begin{array}{l}\text { Exports in } \\
\text { output (\%) }\end{array}$ & $\begin{array}{l}\text { Imports in } \\
\text { demand (\%) }\end{array}$ \\
\cline { 2 - 4 } & Value-added & Exports & Imports & & \\
\hline Total economy & 100 & 100 & 86.1 & 18.9 & 26.0 \\
Agriculture & 27.7 & 10.1 & 7.8 & 7.7 & 10.3 \\
Crops & 20.5 & 5.8 & 7.6 & 5.8 & 13.4 \\
Livestock & 2.0 & 0.0 & 0.1 & 0.0 & 2.5 \\
Forestry & 3.3 & 1.0 & 0.0 & 6.7 & 0.0 \\
Fisheries & 1.8 & 3.3 & 0.0 & 28.1 & 0.0 \\
Mining & 1.6 & 9.6 & 1.5 & 95.4 & 75.5 \\
Manufacturing & 15.4 & 57.2 & 56.5 & 36.9 & 45.5 \\
Foods & 4.2 & 3.1 & 12.8 & 3.5 & 21.1 \\
Metals & 7.4 & 50.7 & 2.2 & 100.0 & 99.3 \\
Petroleum & 0.0 & 0.0 & 13.9 & 0.0 & 100.0 \\
Electricity and water & 5.9 & 9.7 & 4.4 & 36.8 & 24.9 \\
Construction & 3.1 & 0.6 & 1.6 & 2.5 & 7.6 \\
Services & 46.4 & 13.4 & 20.6 & 5.6 & 10.2 \\
Trade & 16.8 & 5.8 & 0.0 & 9.0 & 0.0 \\
Transport & 9.8 & 5.2 & 8.8 & 7.5 & 14.9 \\
Government & 9.6 & 0.0 & 0.0 & 0.0 & 0.0 \\
\hline
\end{tabular}

2007 Mozambique social accounting matrix

livelihood. Despite this high concentration of employment, the agricultural sector (i.e., crops, livestock, forestry and fishing) generates only $28 \%$ of value-added. Low average productivity in agriculture, combined with a lack of employment opportunities in non-agricultural sectors for low skilled labor, implies low incomes and high levels of poverty for most of the population.

Other salient features of Mozambique include a high dependence on metals exports, particularly aluminum, which is largely an enclave activity with few linkages to other sectors. Electricity, most of which is from hydropower, is also a major sector and a significant source of foreign exchange. As part of the Southern African Power Pool, Mozambique is both an importer and exporter of electricity. Importantly, petroleum represents a major import item at about $14 \%$ of total imports. In addition, many other chemical imports contain items with high petroleum content, e.g., fertilizers and plastics. This dependence on imported petroleum is a typical feature of poor African economies. Unlike petroleum, Mozambique's agricultural trade is more balanced, with a deficit of only $1.6 \%$ of GDP. Finally, the country covers a large geographic area and so trade and transport services also represent a substantial share of valueadded. Overall, Mozambique's economic structure in 2007 is fairly typical of low-income African economies. ${ }^{1}$

\footnotetext{
${ }^{1}$ It has recently become clear that Mozambique possesses substantial natural resources. As the focus of this analysis is on climate change impacts under the assumption of unconstrained emissions, we opt to avoid the complications of projecting the impacts of natural resource exploitation. Instead, we assume that net foreign resource availability from aid, natural resource rents, or other capital inflows grows from a bit more than USD 1 billion to about USD3 billion in real terms by 2050 .
} 


\subsection{Economywide model}

The impact of climate change is simulated using a dynamic computable general equilibrium (CGE) model. These models have features making them suitable for this analysis. First, they simulate the functioning of a market economy, including markets for labor, capital and commodities. Second, the structural nature of these models permits consideration of new phenomena, such as climate change. Changes in economic conditions are mediated through prices and markets allowing for a degree of endogenous adaptation. For example, if dryer conditions result in reduced hydropower exports, the real exchange rate will adjust in order to conserve foreign exchange by reducing imports and generate foreign exchange by increasing exports from other sectors. Third, these models assure that all economywide constraints are respected. This is critical discipline for long run projections such as those necessary for climate change. Finally, CGE models contain detailed sector breakdowns and provide a "simulation laboratory" for quantitatively examining how various impact channels influence the performance and structure of the economy.

The Mozambique CGE model contains 31 commodities and four regions (North, Center, South and an urban zone). Production from 10 agricultural activities is divided by region. This is important for analysis of climate change as, for example, growing conditions might improve (deteriorate) in the South while deteriorating (improving) in the North. Non-agricultural activities map one-to-one to non-agricultural commodities and are assumed to be produced in the single urban zone. There are four primary product processing activities that capture linkages between primary product production and related manufacturing. Seven basic factors of production are identified: four types of labor (uneducated and those with primary, secondary, and tertiary levels of education), agricultural land, livestock and capital. The land and livestock are distributed across the three regions of Mozambique (North, Center and South). This detail captures Mozambique's economic structure and influences model results.

Climate change is expected to have implications within specific years (e.g., a higher frequency of severe drought) and over time largely through influence on accumulation processes for capital and technology. To capture these accumulation processes, a recursive dynamic specification is adopted whereby, among other growth processes, savings and investment in year $t$ determines the availability of new productive capital in year $t+1$. The model is solved annually over the 43-year simulation period 2007-2050. In addition, a road infrastructure module is incorporated directly into the CGE model. This roads module explicitly accounts for the accumulation of capital in the form of a road network (Chinowsky et al. 2013 and Arndt et al. 2012). Events that reduce stocks of productive assets, such as flood events that wash away roads or cyclone strikes that destroy other capital stocks, have the potential to materially slow overall economic growth especially if climate change substantially augments the frequency or severity of these events. ${ }^{2}$

\section{Climate change impact channels}

The analysis proceeds by establishing a baseline economic scenario running to 2050 where climate change impacts are absent. We then impose successive climate change impact channels. Four major impact channels are identified: agriculture, roads, hydropower, and the

\footnotetext{
${ }^{2}$ For a detailed exposition of the core dynamic CGE model see Diao and Thurlow (2012) while more details on the climate change formulations and shocks imposed can be found in Arndt and Thurlow (2013).
} 
combination of sea level rise and cyclone strike. We discuss the baseline and then each of the impact channels in turn.

\subsection{Baseline}

The objective of the Baseline scenario is to set plausible values for general economic growth determinants. Unless these determinants are affected by climate change, their values remain constant across all scenarios. By holding all determinants constant, except those affected by climate change, the implications of climate change for economic growth can be inferred.

The CGE model is solved annually over the 43-year period 2007-2050. Historical climate variability is introduced into the baseline path by assuming that 40 years of historical annual weather repeats itself over the period 2011 to 2050, which we take as a no climate change scenario. These climate variations affect annual agricultural and hydropower output. In addition, economic and climate outcomes establish a baseline level for road network expansion out to 2050. In addition, the world price projections developed by Paltsev (2012) are incorporated into the baseline. This is done because world price changes and climate change will interact. For example, Paltsev projects a $23 \%$ increase in the real price of agricultural products by 2050 under the assumption of unconstrained emissions. With these world price increases, the welfare implications of productivity declines in agriculture may be magnified because the option of importing food in order to make up for these shortfalls is no longer as attractive. In addition, petroleum prices are projected to nearly triple by 2050 under unconstrained emissions. As noted, Mozambique, like most least developed countries, currently imports nearly all hydrocarbons consumed and hydrocarbons, particularly petroleum, represent a substantial import item.

Other growth determinants incorporated into the baseline, but assumed to be unaffected by climate change, include population and labor supply, improvements in national educational attainment, and crop land expansion. These are calibrated to future projections, such as the United Nations' population forecasts and recent trends in crop land area. Together the baseline assumptions result in a GDP growth rate of about $5 \%$ per annum between 2007 and 2050. In per capita terms, this translates to a growth rate of about $3.6 \%$ per year. This reflects a gradual slowing down of Mozambique's strong economic growth over the last two decades. Moreover, the share of crops and livestock in GDP declines in the baseline from about $23 \%$ in 2010 to about $10 \%$ in 2050 . This is consistent with a continuation of recent patterns of economic growth and structural change. We consider the implications of alternative baseline assumptions when presenting our results in the next section. Below we explain how each climate change impact channel considered is evaluated using the CGE model.

\subsection{Agriculture}

In this scenario, climate shocks on crop yields are applied on an annual basis. These shocks are derived from a process-based crop model, CliCrop, which is designed specifically for climate change applications (Fant et al. 2012). CliCrop takes annual precipitation and temperature from the historical series or climate change projections and converts these into annual evapotranspiration. This is compared to potential evapotranspiration, derived using regional soil and crop characteristics, in order to estimate how crop yields in a given year deviate from the potential yield obtained under normal weather conditions. The estimated yield deviations are scaled to match the yields and weather outcomes in our model's 2007 base year.

Agricultural impacts are described in detail in Fant et al. (2013). Briefly, the majority of climate outcomes lead to declining yields for rain-fed crops, though both positive and negative 
crop yield implications are possible for nearly all crops under alternative climate projections. By around 2050, across all climate scenarios, yields are expected to decline by about 3-4\% on average relative to the baseline path, although declines of greater than $10 \%$ for some crops are possible in specific climate scenarios. ${ }^{3}$ A recent meta-analysis of crop yield impacts in Africa and Asia by Knox et al. (2012) provides a useful point of comparison. The estimates generated by Fant et al. fit comfortably within the range of impacts by 2050 reported by Knox et al. (2012). While within the range, the estimates of Fant et al. (2013) tend to be slightly more optimistic than the median reported by Knox et al. (2012) for 2050.

Crop land and capital allocations within agriculture are determined in the CGE model on the basis of expected yields and prices, allowing for endogenous adaptation. In each year, climate realizations (weather) causes deviations (both positive and negative) from expected yield levels. As with the crop model, the CGE model includes production functions for each crop in each subnational region. The estimated annual yields from CliCrop are imposed on the CGE model by adjusting each regional crop's baseline level of total factor productivity (TFP). This assumes that farm labor productivity declines alongside the land yields from CliCrop. It is important to highlight that, in the CGE model, the baseline rate of technical advance in agriculture is unaffected by climate change, with climate causing annual deviations around the baseline trend. When weather conditions result in production declines, the baseline productive capacity of the land remains unaffected. Consequently, productivity levels are able to rebound if weather in a particular year returns to baseline conditions (Benson and Clay 1998).

\subsection{Roads}

Road impact shocks are explained in detail in Chinowsky et al. (2013). Briefly, changes in temperature, precipitation, and the frequency/severity of flooding events can have strong impacts on road infrastructure. Events that destroy infrastructure, such as fast moving floods across roads, tend to reduce economic growth (Noy 2009). Floods eliminate both private and public capital. With respect to roads and in the absence of insurance mechanisms, the fiscal budget that would have been directed towards expanding the quality and density of the network must be redirected to replacing the infrastructure lost. The result of heightened flood frequency/intensity is a smaller and lower quality road network.

Looking to the longer term, there is substantial evidence that road network quality can be a significant determinant of economywide productivity growth. For example, the seminal work of Fernald (1999) concluded that public investment, principally in roads, "contributed about one percentage point to total factor productivity growth" (p. 620) during the period 1953-1973 in the United States. For developing countries, Arndt et al. (2012) review both the cross country and country case literature related to road infrastructure. They conclude that the weight of the evidence points to reasonably strong externalities in terms of productivity growth from expansion of road networks in terms of quality and quantity.

Alongside agriculture, Fant et al. (2013) employ the CliRun model in order to convert changes in temperature and precipitation into changes in runoff and flood return periods. They find that, for an important subset of climate scenarios, dramatically reduced return periods on major flood events are expected in Mozambique by the 2040s. Chinowsky et al. (2013) explore the implications of these changes for roads using a dedicated roads model (CliRoad). As noted earlier, a version of this road model is incorporated directly into the CGE model allowing for detailed accounting of growth in road stocks given budgets (modeled

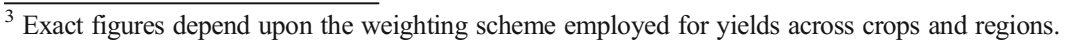


as a fixed share of government expenditure) and the implications of climate changes for maintenance and rehabilitation expenses. More specifically, the model contains stressorresponse functions for different road surfaces (e.g., paved and unpaved). These functions are calibrated to Mozambique road and weather conditions, and convert heat stress, rainfall and flooding into annual estimates of maintenance costs. If these costs rise relative to the baseline then they displace investment in new roads leading to a shorter road network length over time.

Following Arndt et al. (2012), we assume in the CGE model that sector-specific productivity growth (excluding hydropower and aluminum production) is a function of the ratio of road network length relative to the baseline. Previously, the square root of this ratio was taken; however, this form has the undesirable property of reducing the marginal impact of strong events. In addition, the CliRun and CliRoad modeling combination has been updated since initial development in 2010 with generally less sensitivity to given climatic conditions particularly at the extremes. As indicated in Chinowsky and Arndt (2012), no published ex post studies of infrastructure damage following major flood events exist. Hence, it is most practical to calibrate between historical data on climatic conditions and economic growth data, both of which are available. For this analysis, a proportional relationship fits best. So, if the rate of productivity growth in non-agricultural sectors is $2.6 \%$ per annum in 2049 in the baseline and the size of the road network in climate scenario $i$ is projected to be $95 \%$ of the baseline in the roads model, then productivity growth in non-agricultural sectors in climate scenario $i$ in 2049 is assumed to be $2.6^{*} .95=2.47 \%$.

\subsection{Hydropower}

Fant et al. (2013) also use river basin models to estimate annual streamflow at different points along the Zambezi river for each climate scenario in the HFD. This is converted into annual hydropower generation levels based on the capacity of existing and planned infrastructure. As with the crop models, annual hydropower supply in each climate scenario is converted into deviations from baseline. The CGE model disaggregates Mozambique's electricity sector into coal-fired plants, hydropower dams, and other sources. Deviations in hydropower supply are imposed on baseline TFP levels in the model's hydropower production function. Proportional shocks are applied. If the hydropower modeling indicates that actual production in the year $t$ is $95 \%(105 \%)$ of the baseline level due to decreased (increased) river flow, then hydropower production is reduced (augmented) by the same proportion while input use remains constant.

\subsection{Sea level rise and cyclones}

Unlike all preceding shocks, sea level rise and cyclones are uniformly negative shocks for growth and development. Sea level rise is assumed to reduce the area of arable land available for production as coastal arable land becomes submerged, i.e., an unmitigated bad. Cyclones are more complex but also uniformly negative (at least as modeled here). Neumann et al. (2013) consider these impacts in detail. Briefly, sea level rise provides an advanced starting point for the storm surges associated with cyclones, i.e., a physically higher platform that allows storm surge to reach further inland and cause greater damages. As in Neumann et al., we assume that climate change does not increase (or decrease) the frequency or severity of cyclone themselves. Instead, we focus on the marginal impact of storm surges from cyclones due to sea level rise. The other effects of cyclones, such as wind damage, are assumed to be constant between the climate change and no climate change scenarios.

Neumann et al. use a seeded cyclone generator and coastal storm surge model to estimate the GDP losses associated with cyclones, as well as how these losses are amplified by rising 
sea levels. We convert the estimated GDP losses into percentage changes in capital stocks, which, in the CGE model, are assumed to become immobile after investment. We impose annual capital stock losses on the model based on a fixed set of randomly-drawn cyclones events. Note that the same series of annual cyclone events is applied to all scenarios. Over time, however, rising sea levels increases potential cyclone damages relative to the baseline due to more pronounced inland storm surge.

\section{Simulation results}

We begin by focusing on changes to agricultural value added when only climate change impacts on crop yields are considered (scenario Agriculture). Figure 1 shows the estimated HFD of agricultural impacts when the definition of agriculture is restricted to crops and livestock. The horizontal axis reports the percentage change in the average of value added in agriculture over the period 2046-2050 relative to the baseline. We present a five-year average because final-year results are more likely to reflect inter-annual weather variability rather than long-term climate change. We initially focus on the final five years of our simulation period so that the estimated losses include the cumulative effects of annual climate shocks during all preceding years. The vertical axis in the figure reports the estimated density, which is a measure of likelihood. The mode of the distribution centers around about a $4 \%$ decline in total agricultural value added. Declines of up to $10 \%$ are possible. It is also possible, but unlikely, that agricultural value added increases.

The second simulation scenario involves roads. Figure 2 uses the same graphical format to consider road network length by decade. We elect to present the total effect on road network length from the final scenario where all climate change impact channels considered are included. In the 2010s, when very few climate change impacts are present, the median impact on roads is actually marginally positive. However, the average or expected impact is almost exactly zero due to the presence of a negative tail in the HFD. As time progresses, the mode of the distribution shifts to the left, and the distribution also becomes progressively skewed to the left. By the 2040s, the average length of the road network is always smaller than in the

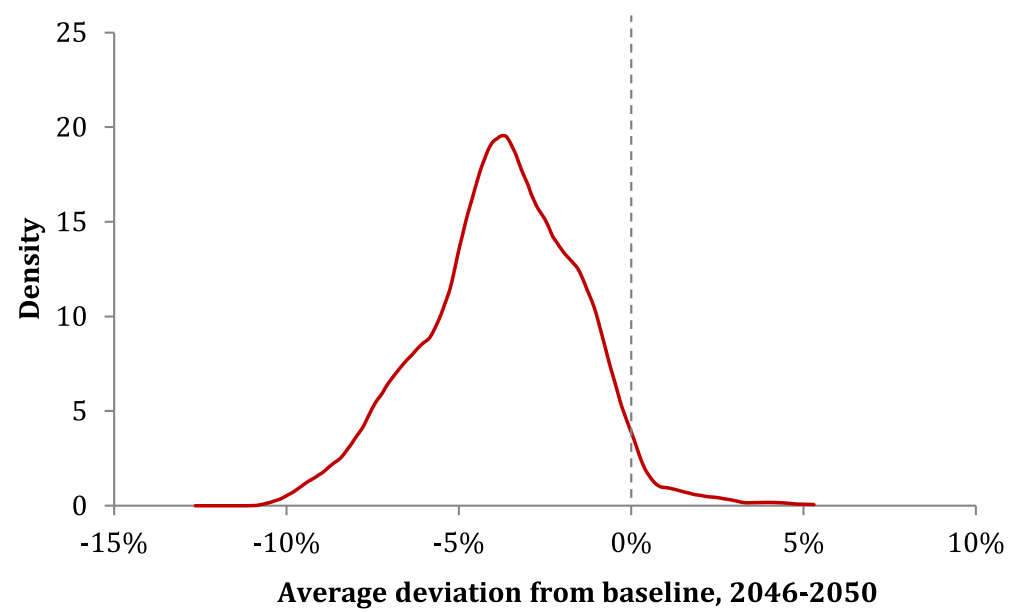

Fig. 1 Value added in agriculture relative to the baseline for the Agriculture scenario, 2046-2050 


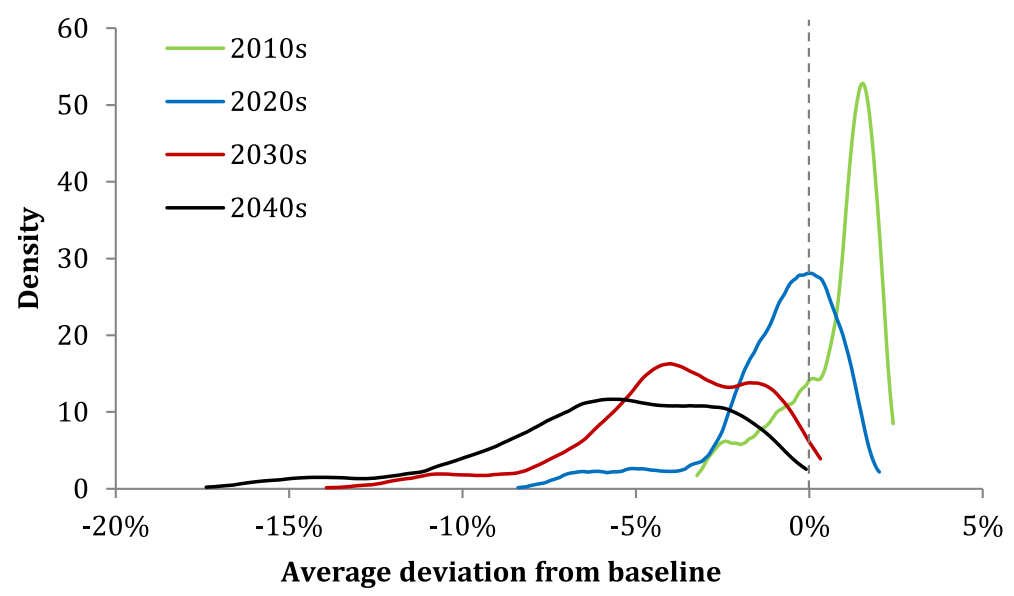

Fig. 2 Impacts on average road network length by decade for the final cumulative Cyclone scenario

baseline. Strongly negative outcomes in terms of road network length are associated with dramatic increases in the return periods for major flood events.

Figure 3 illustrates the implications of all shocks considered for total GDP at factor cost. As noted, the effects are cumulative as climate impact channels are added and imposed in the same order as presented in Section 3. The final Cyclone scenario includes all impact channels. The horizontal axis reports the percentage change in the average of GDP at factor cost over the period 2046-2050 relative to the baseline, and the vertical axis reports the density or measure of likelihood.

The dark vertical dashed line shows the mean effect from the scenario Agriculture on total value added (the HFD for the scenario Agriculture is omitted because of limited variation around the mean). This impact is a bit more than $0.4 \%$ of GDP, which is sensible given that

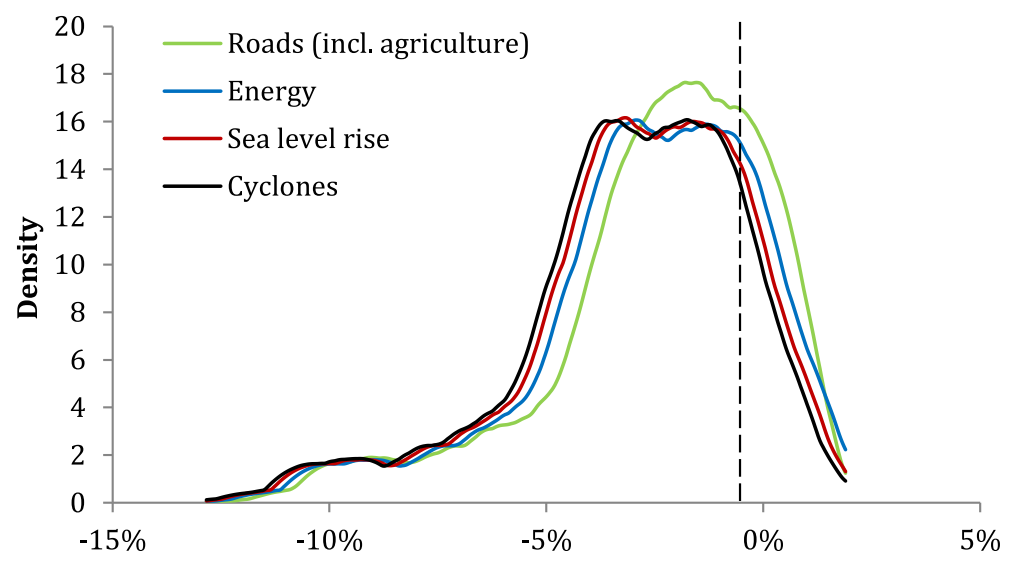

Average deviation from baseline, 2046-2050

Fig. 3 Percent deviation of GDP at factor cost relative to baseline, 2046-2050. The vertical dashed line represents the mean impact of the agriculture scenario. Note: The Cyclone scenario depicts the cumulative effect of all impact channels 
the impacts on agricultural value added alone are about $4 \%$ and the agricultural share of GDP is about $10 \%$.

The next effect modeled is roads. As Fig. 2 indicates, this is a major potential source of impact. The effect of roads is to expand the range of potential impacts dramatically. The large bulk (about $86 \%$ ) of potential outcomes, considering the combined effect of Agriculture and Roads only, lie between about minus five percent and plus two percent of GDP. There are no strongly positive outcomes; however, for the first time, strongly negative outcomes are introduced with about $14 \%$ of outcomes stronger than minus five percent of GDP and about $1.5 \%$ of outcomes stronger than $-10 \%$ of GDP. So, while the expected impact of climate change in the scenario Roads is not enormous at about $-2.4 \%$ of GDP, the road channel substantially increases the range of potential outcomes.

Hydropower is the next impact channel added. As discussed in Fant et al. (2013), impacts on hydropower in Mozambique are negative on average. The shape of the distribution of GDP outcomes is largely similar to that of Roads but with a small shift to the left. The mean climate change impact increases by not quite $0.3 \%$ of GDP bringing the mean total impact up to about $-2.7 \%$ of GDP.

As discussed above, the effects of sea level rise and cyclones are uniformly negative. The distribution again shifts to the left by about $0.2 \%$ of GDP for each effect. The expected loss of GDP is thus about $-3.1 \%$ when all impact channels are included (e.g., the scenario Cyclones). This mean disguises a great deal of information that the hybrid frequency distributions reveal. As noted in the Introduction, impacts greater than $10 \%$ of GDP in about 2050 are possible but unlikely with about a $2.5 \%$ probability of occurrence. The majority of outcomes, about $73 \%$, lie within zero and five percent of GDP. The probability of positive GDP outcomes by 2050 is small but non-negligible at slightly less than nine percent.

Overall, more than four out of five outcomes imply losses less than five percent of GDP. In per capita terms, GDP losses of less than five percent by about 2050 imply a growth delay of less than two years. In other words, if the economy is five percent smaller in 2050 as a result of climate change, the economy could be expected to attain the no climate change level of per capita GDP sometime during 2052. Viewed through this optic, climate change does not appear to exert a large influence at least out to 2050. However, in many scenarios, the people of Mozambique, who are already among the poorest in the world, are experiencing sustained losses for long periods as a result of climate change (even when the analysis extends only to 2050).

These sustained losses can be captured via a calculation of the net present value (NPV) of GDP losses using a $5 \%$ discount rate. Table 2 shows the probability of falling into one of four categories in terms of losses for each scenario as well as the mean loss by scenario. Overall, the

Table 2 Mean net present value of losses and probability of loss by category and scenario

\begin{tabular}{|c|c|c|c|c|c|}
\hline & Agriculture & Roads & Energy & SLR & Cyclone \\
\hline Mean (2007 USD billion) ${ }^{a}$ & -1.19 & -2.34 & -3.42 & -3.66 & -3.85 \\
\hline Prob. loss $>10$ Billion & 0.0 & 3.6 & 5.1 & 5.7 & 6.2 \\
\hline Prob. loss 5-10 Billion & 0.0 & 12.3 & 24.4 & 26.4 & 28.0 \\
\hline Prob. loss $0-5$ Billion & 91.9 & 60.7 & 51.9 & 51.3 & 50.6 \\
\hline Prob. of gain & 8.1 & 23.5 & 18.5 & 16.7 & 15.3 \\
\hline
\end{tabular}

Scenarios are cumulative. The Cyclone scenario is the final one with all impact channels included

${ }^{\text {a }}$ Values are real 2007 USD and a discount rate of five percent is applied 
support of the distribution of the NPV of GDP changes imposed by climate change is very wide running from a 15 billion USD loss to a five billion USD gain. The probability of a gain in NPV terms, at about $15 \%$, is about six percentage points bigger than the probability of a larger economy in 2050 (see Fig. 3). This occurs because climate change impacts may be positive for an extended period before turning negative in the late 2040s. This compilation of effects through time combined with the effect of discounting on later period losses explains the increased probability of gain in NPV terms. While positive outcomes are present, the large bulk of outcomes are negative with many of them strongly so. The probability that total losses to 2050 will exceed five billion USD is more than one in three. The probability of losses greater than 10 billion is about $6 \%$. Viewed in this way, the losses imposed by climate change are significant.

Figure 4 presents the NPV of losses by decade for the final cumulative Cyclone scenario. The graph points to progressively stronger impacts through time with the 2040s generating on average the strongest climate change impacts in present value terms. As might be expected, the variance of impacts also increases with time. The range of outcomes in the 2010s is small relative to later decades. The distributions then become progressively wider culminating in the distribution of possible outcomes in the 2040s, which is by far the widest. Recalling that the baseline growth rate is very similar to the discount rate at about five percent, Fig. 4 illustrates that climate change shocks are tending to become larger with time relative to the size of the total economy.

Finally, we consider the sensitivity of our results to changes in the sectoral pattern of baseline economic growth. We assumed that agriculture in the baseline declines in importance with crops and livestock accounting for only $10 \%$ of national GDP by 2050 , down from $23 \%$ in 2007. As such, while Fig. 1 reported a $4 \%$ decline in agricultural GDP at the mode of the HFD, this translates into only a $0.4 \%$ decline in total GDP by 2050 . Had agriculture retained its $23 \%$ share of GDP throughout the baseline, then the mode of total GDP losses from agriculture is only slightly larger at $0.5 \%$. Conversely, energy, roads and cyclones have larger impacts on nonagricultural GDP and so by increasing the share of agriculture in baseline GDP we reduce the nonagricultural GDP losses from these three channels. If agriculture's share of GDP remained at $23 \%$ in the baseline, then the combined GDP losses from climate change are

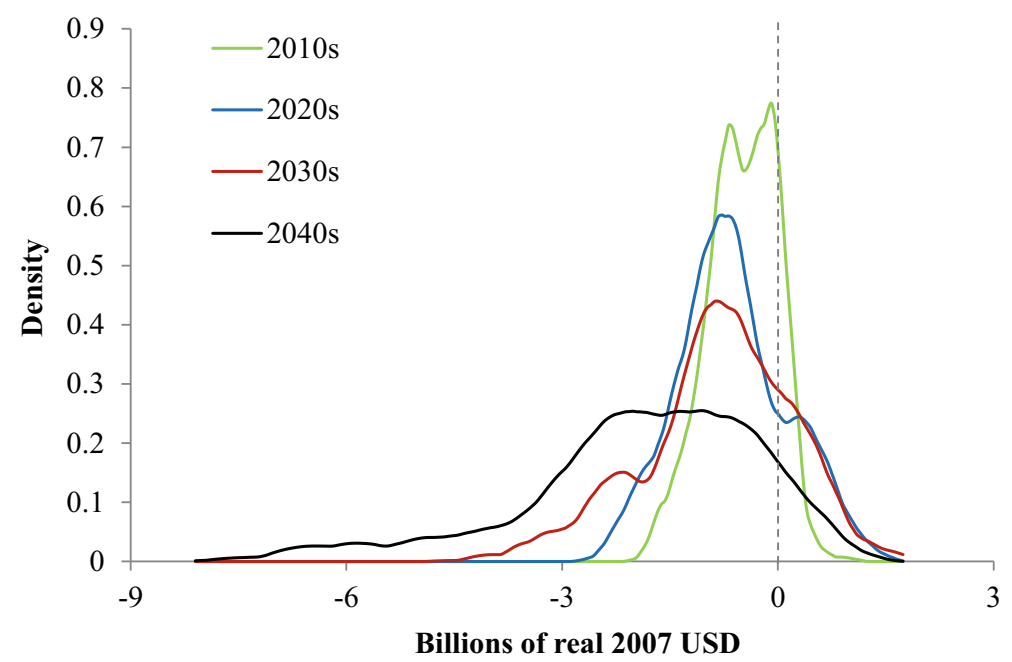

Fig. 4 Net present value of GDP losses by decade for the cumulative impact (Cyclone) scenario 
smaller, i.e., the mode of the GDP losses for the final cumulative Cyclone scenario in Fig. 3 is $4.2 \%$ instead of $4.7 \%$. From this we conclude that, while the baseline pattern of growth influences measured impacts, our results are robust to a wide range of baseline assumptions.

\section{Conclusions}

The articles in this special issue take a probabilistic approach to assessing climate change risks and vulnerabilities. This approach has at least three principal advantages. First, it provides a much more comprehensive and useful picture for decision-makers. To date, analysts have been forced to state that climate change impacts might be large, small, or even positive without any formal mechanism for estimating the probability of a given outcome. For Mozambique, we find that more than four out of five outcomes imply losses less than five percent of GDP relative to a fictional no climate change baseline. Strongly negative outcomes, a reduction of greater $10 \%$ of GDP relative to baseline, are possible but unlikely (less than $2 \%$ probability). Nevertheless, consistent losses tend to be imposed resulting in a high probability of substantial GDP losses in NPV terms.

Second, the probabilistic approach provides much more detailed insight into the importance of various impact channels including the possibility of capturing interactions between impact channels across the range of potential future climates. For Mozambique, the flooding impact channel is the principal driver of variance in outcomes and the driver of all strongly negative outcomes. This channel merits attention both in terms of current policy and future research.

Finally, the probabilistic approach provides a more holistic and comprehensive approach for evaluating adaptation options. Adaptation policy is constrained by uncertainties concerning the exact nature of climate change. Most obviously, adoption of measures to cope with a dryer future when a wetter future is possible risks not only wasting resources but being counterproductive. The probabilistic approach applied here to Mozambique highlights the importance of no regret, flexible and/or robust options as recommended by Hallegatte (2009) among others.

\section{References}

Arndt C, Chinowsky P, Strzepek K, Thurlow J (2012) Climate change, growth and infrastructure investment: the case of Mozambique. Rev Dev Econ 16(3):463-475

Arndt C, Fant C, Robinson S, Strzepek K (2014) Informed selection of future climates. Clim Chang. doi:10.1007/ s10584-014-1159-3

Arndt C, Strzepek K, Tarp F, Thurlow J, Fant C, Wright L (2011) Adapting to climate change: an integrated biophysical and economic analysis for Mozambique. Sustain Sci 6(1):7-20

Arndt C, Thurlow J (2013) Climate uncertainty and economic development: evaluating the case of Mozambique to 2050. Working paper 2013/042. World Institute for Development Economics Research, Helsinki

Benson C, Clay E (1998) The impact of drought on Sub-Saharan African economies: a preliminary examination. Technical Paper No. 401. World Bank, Washington, DC

Chinowsky PS, Arndt C (2012) Climate change and roads: a dynamic stressor-response model. Rev Dev Econ 16(3):448-462

Chinowsky PS, Schweikert AE, Strzepek NL, Strzepek K (2013) Infrastructure and climate change: impacts and adaptations for the Zambezi river valley. Working paper 2013/041. World Institute for Development Economics Research, Helsinki [accepted in Climatic Change]

Diao X, Thurlow J (2012) A recursive dynamic computable general equilibrium model. In: Diao X, Thurlow J, Benin S, Fan S (eds) Strategies and priorities for African agriculture: economywide perspectives from country studies. Washington DC, USA, International Food Policy Research Institute 
Fant C, Gebretsadik Y, Strzepek K (2013) Impacts of climate change on crops, irrigation and hydropower in the Zambezi river basin. Working paper 2013/039. World Institute for Development Economics Research, Helsinki [citation to be switched to special issue if accepted]

Fant C, Gueneau A, Strzepek K, Awadalla S, Farmer W, Blanc E, Schlosser CA (2012) CliCrop: A crop waterstress and irrigation demand model for an integrated global assessment modeling approach. Report 214, Joint Program on the Science and Policy of Global Change, MIT, Cambridge MA.

Fernald JG (1999) Roads to prosperity? Assessing the link between public capital and productivity. Am Econ Rev 89:619-38

Hallegatte S (2009) Strategies to adapt to an uncertain climate change. Global Env Chang 19:240-247

Knox J, Hess T, Daccache A, Wheeler T (2012) Climate change impacts on crop productivity in Africa and South Asia. Environ Res Lett 7:1-8

Neumann J, Emanual KA, Ravela S, Luwig LC, Verly C (2013) Assessing the risk of cyclone-induced storm surge and sea level rise in Mozambique. Working paper 2012/065. World Institute for Development Economics Research, Helsinki

Noy I (2009) The macroeconomic consequences of natural disasters. J Dev Econ 88:221-231

Paltsev S (2012) Implication of alternative mitigation policies on world prices for fossil fuels and agricultural products. Working paper 2012/065. World Institute for Development Economics Research, Helsinki

Schlosser CA, Strzepek K (2013) Regional climate change of the greater Zambezi river basin: a hybrid assessment. Working paper 2013/071. World Institute for Development Economics Research, Helsinki [accepted in Climatic Change] 